WINCK, C.A. et al. Produção de leite no Brasil: qualidade, mercado internacional e agricultura familiar. PUBVET, Londrina, V. 5, N. 32, Ed. 179, Art. 1210, 2011.

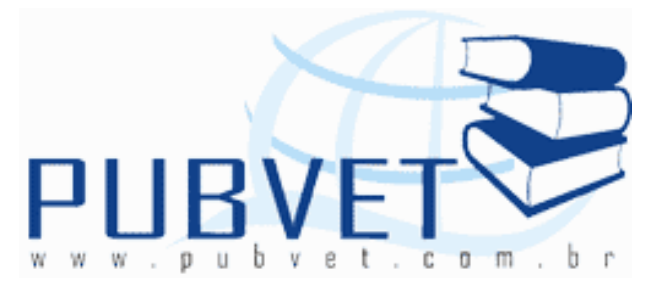

PUBVET, Publicações em Medicina Veterinária e Zootecnia.

\title{
Produção de leite no Brasil: qualidade, mercado internacional e agricultura familiar
}

\section{César Augustus Winck ${ }^{1}$; Alex Leonardi²; Miguelangelo Gianezini²; Clandio Favarini Ruviaro²; João Armando Dessimon Machado ${ }^{3}$}

1 Doutorando em Agronegócios CEPAN/UFRGS e Professor da UNOESC. cesar.cepan@gmail.com

2 Doutorando em Agronegócios CEPAN/UFRGS;

${ }^{3}$ Professor Associado da UFRGS

\section{Resumo}

A atividade leiteira vem se destacando nos últimos anos no Brasil, por se configurar como uma das principais atividades econômicas geradoras de emprego e renda. O setor leiteiro está inserido em um ambiente onde há forte concorrência, e desse modo, os produtores, em especial os de escala reduzida, necessitam de auxilio para a comercialização de seus produtos de modo a se manterem no mercado. Focando na qualidade do leite cru produzido, fonte primordial para que todos os produtos lácteos sejam industrializados e comercializados, é necessário entender que o leite é um alimento nobre e altamente perecível, sendo necessário dar atenção à qualidade do mesmo. Historicamente as normas brasileiras de qualidade do leite tiveram seu enfoque voltado ao processo de industrialização e qualidade do produto final, colocando em segundo plano a qualidade da matéria prima. A Instrução 
WINCK, C.A. et al. Produção de leite no Brasil: qualidade, mercado internacional e agricultura familiar. PUBVET, Londrina, V. 5, N. 32, Ed. 179, Art. 1210, 2011.

Normativa 51 (IN 51) editada pelo Ministério da Agricultura, Pecuária e Abastecimento (Brasil, 2002) e implantada em julho de 2005 nos Estados do Sul, Sudeste e Centro-oeste, teve entre seus objetivos, padronizar a qualidade do leite cru produzido no país, procurando melhorar a qualidade para o mercado interno e tornando-o competitivo no mercado internacional. Parcela significativa dos produtores de leite brasileiros, ainda não está preparada para enfrentar as exigências da IN 51 e estes produtores poderão ser excluídos da cadeia produtiva, caso não se adaptem a esta nova realidade. $O$ enfoque do estudo é abordar o mercado lácteo nacional, discutindo aspectos de qualidade higiênica mínima e a manutenção do produtor de leite brasileiro na cadeia produtiva, buscando compreender como é possível produzir dentro das normas, sem excluir parcela significativa dos milhares de produtores brasileiros, que dependem do leite para a manutenção de mensal das propriedades e das famílias agricultoras.

Palavras-chave: Produtor rural; IN 51; Segurança alimentar

\section{Milk production in Brazil: quality, international market and family farm}

\section{Abstract}

Milk production has been increasing in recent years in Brazil, up becoming one of the main economic activities that generate employment and income. The dairy sector is housed in an environment where there is strong competition, and thus the producers, especially small-scale, need help to market their products in order to remain on the market. Focusing on quality of raw milk produced, the primary source for all dairy products are manufactured and marketed, it is necessary to understand that milk is a noble and highly perishable food, being necessary to give attention to quality.Historically, Brazilian standards of quality milk had turned its focus to the industrialization process and final product quality by putting in the background quality of raw materials.The Normative 51 (NI 51) published by the Ministry of Agriculture, Livestock and Supply (Brazil, 2002) and implemented in July 2005 in the 
WINCK, C.A. et al. Produção de leite no Brasil: qualidade, mercado internacional e agricultura familiar. PUBVET, Londrina, V. 5, N. 32, Ed. 179, Art. 1210, 2011.

South, Southeast and Midwest, had among its objectives, to standardize the quality of raw milk produced in the country, seeking to improve the quality for the domestic market and making it competitive in the international market. Significant portion of milk producers in Brazil still is not ready to face the demands of IN 51 and these producers will be excluded from the chain, if not adapted to this new reality. The focus of the study is to address the national dairy market, discussing aspects of hygienic quality and minimal maintenance of the milk producer in the Brazilian productive chain, trying to understand how you can make within the rules, not excluding a significant portion of the thousands of Brazilian producers, who depend milk for the maintenance of the properties and monthly agricultural families.

Key-words: Farmer; NI 51; Food safety

\section{INTRODUÇÃO}

No atual mercado competitivo e globalizado, produzir leite e derivados com qualidade é requisito obrigatório. A segurança alimentar é um dos temas mais debatidos na atualidade, dando ênfase, do ponto de vista social, ambiental e econômico, à produção de alimentos por métodos sustentáveis, levando-se em conta a produção de alimentos seguros, saudáveis e nutritivos.

O leite é uma mistura complexa, nutritiva e estável de gordura, proteínas, minerais e vitaminas. Além disso, muitos componentes do leite têm mostrado efeitos benéficos sobre a saúde, caracterizando seu valor funcional. Contudo, é um produto delicado e altamente perecível, tendo suas características físicas, químicas e biológicas facilmente alteradas pela ação de microrganismos e pela manipulação a que é submetida.

Assim, o Ministério da Agricultura, Pecuária e Abastecimento - MAPA publicou a Instrução Normativa 51/2002, com novos regulamentos técnicos para produção, identidade e qualidade para os diferentes tipos de leite, bem como as condições para a sua refrigeração na propriedade rural e o transporte do leite até a indústria, visando suprir uma deficiência na legislação brasileira. 
WINCK, C.A. et al. Produção de leite no Brasil: qualidade, mercado internacional e agricultura familiar. PUBVET, Londrina, V. 5, N. 32, Ed. 179, Art. 1210, 2011.

Dessa forma, e no atual contexto de globalização dos mercados, descuidar-se da qualidade da inocuidade dos produtos lácteos é arriscar a perda dos mercados interno e de exportação. E a garantia da inocuidade do leite e seus derivados é o produto do esforço combinado de todos os integrantes da cadeia produtiva, traduzindo-se em ações coordenadas e integradas de controle de qualidade dos alimentos e sua certificação através de todo o processo de produção, coleta, transporte, processamento, armazenamento e comercialização dos produtos.

Todo este contexto depende também da manutenção dos agricultores na produção, sejam eles produtores de porte pequeno, médio ou grande. Não se concebe a exclusão destes por falhas na produção, sejam elas de origem higiênica, microbiológica ou sanitária, visto que parcela significativa da renda mensal de grande parte dos agricultores brasileiros provém da produção de leite, além da produção para a subsistência da família rural.

\section{METODOLOGIA}

Com base nos objetivos, essa pesquisa é classificada como exploratória, onde o escopo é proporcionar uma visão geral acerca de determinado fato (GIL, 2008), qual seja a cadeia produtiva do leite no Brasil.

Seguindo classificação proposta por Gil (2008), com base nos procedimentos técnicos esse trabalho é qualificado como uma pesquisa documental, sendo a coleta de dados obtida de fontes diversificadas e dispersas, podendo englobar arquivos de órgãos públicos e privados (GIL, 2008). Nesse sentido, a coleta de dados foi realizada em materiais publicados em livros, revistas, jornais, redes eletrônicas, sendo realizada em bases de pesquisa nacionais e internacionais.

Os materiais recolhidos foram submetidos à Leitura Informativa que tem por objetivo coletar e analisar dados ou informações que serão utilizados em trabalhos para responder a questões específicas (CERVO \& BERVIAN, 1996).

Este tipo de leitura contempla quatro passos cronológicos, conforme segue: leitura de reconhecimento e pré-leitura, com o objetivo de certificar-se 
WINCK, C.A. et al. Produção de leite no Brasil: qualidade, mercado internacional e agricultura familiar. PUBVET, Londrina, V. 5, N. 32, Ed. 179, Art. 1210, 2011.

da existência das informações que se procura; a leitura seletiva que tem a finalidade de eliminar o dispensável e fixar-se no que realmente é de interesse; a leitura crítica ou reflexiva onde o objetivo é saber o que o texto "fala" sobre o assunto; e por fim a leitura interpretativa, onde após a análise e julgamento, procede-se a operação de síntese e apresentação dos dados descobertos (CERVO \& BERVIAN, 1996).

\section{DESENVOLVIMENTO TEÓRICO}

QUALIDADE DO LEITE

O leite é uma mistura complexa, nutritiva e estável de gorduras, proteínas, minerais e vitaminas, completamente dissolvidas na água do leite, formando uma solução com uma composição média de $87,5 \%$ água, 3,8\% gordura, $3,3 \%$ proteína, $4,6 \%$ lactose e $0,8 \%$ minerais e vitaminas (CARVALHO et al., 2006).

O leite, contudo, é produto delicado e altamente perecível, tendo suas características físicas, químicas e biológicas facilmente alteradas pela ação de microrganismos e pela manipulação a que é submetido (DÜRR, 2004). Assim sendo, o leite e produtos lácteos podem levar a surtos de toxinfecções alimentares, causados por uma variedade de microrganismos que encontram no leite um meio ideal de crescimento. Leite fluído e produtos lácteos adequadamente pasteurizados não constituem uma ameaça aos consumidores, desde que a contaminação após a pasteurização seja evitada. Também é importante que o leite não contenha resíduos de antibióticos, desinfetantes ou agentes de limpeza, porque estas substâncias podem ser prejudiciais à saúde dos consumidores e podem interferir na fabricação de produtos lácteos (PHILPOT, 1998).

O Ministério da Agricultura, Pecuária e Abastecimento - MAPA publicou em 2002 a Instrução Normativa 51/2002 (BRASIL, 2002), com novos regulamentos técnicos para a produção, identidade e qualidade para os diferentes tipos de leite, bem como as condições para a sua refrigeração na propriedade rural e transporte do leite até a indústria. Esta publicação vem 
WINCK, C.A. et al. Produção de leite no Brasil: qualidade, mercado internacional e agricultura familiar. PUBVET, Londrina, V. 5, N. 32, Ed. 179, Art. 1210, 2011.

suprir uma deficiência na legislação brasileira, entretanto, somente uma mudança de mentalidade e comportamento em toda a cadeia produtiva do leite propiciará a obtenção de produtos com qualidade.

Segundo os procedimentos específicos para controle de qualidade da matéria-prima, contidos na IN 51, a pesquisa de Contagem de Células Somáticas (CCS) e Contagem Bacteriana Total (CBT) deve ser realizada mensalmente para amostras de tanque do leite de todas as propriedades, em laboratórios credenciados e licenciados pelo MAPA.

$O$ primeiro ponto que deve ser estabelecido quando se discute o termo qualidade do leite é a definição clara e objetiva desse conceito. Basicamente, o leite para ser caracterizado como de boa qualidade deve apresentar as seguintes características organolépticas, nutricionais, físico-químicas e microbiológicas: sabor agradável, alto valor nutritivo, ausência de agentes patogênicos e de contaminantes (antibióticos, pesticidas, adição de água e sujidades), reduzida contagem de células somáticas e baixa carga microbiana (FONSECA E SANTOS, 2000).

A composição do leite é influenciada pelo manejo, genética e alimentação dos animais, enquanto que a qualidade higiênica é influenciada pelo estado sanitário do rebanho e técnicas de obtenção, transporte, armazenamento e distribuição do leite. Portanto, somente vacas sadias, alimentadas e manejadas adequadamente podem produzir leite de qualidade, embora esses cuidados não garantam a qualidade final do produto, uma vez que este percorre um longo caminho até chegar à mesa do consumidor (FONSECA E SANTOS, 2000).

A qualidade higiênica é representada pela ausência de agentes físicos, químicos ou biológicos resultantes da manipulação deficiente da matéria-prima ou dos produtos derivados dela. A inocuidade dos alimentos é muito importante, pois afeta tanto a economia como a saúde pública.

Alguns critérios físico-químicos são normalmente utilizados pelas indústrias de laticínios para avaliar os cuidados dispensados ao leite pelo produtor. Esses critérios são úteis para a indústria controlar o rendimento industrial e a qualidade do produto acabado. Entretanto, se utilizados de forma 
WINCK, C.A. et al. Produção de leite no Brasil: qualidade, mercado internacional e agricultura familiar. PUBVET, Londrina, V. 5, N. 32, Ed. 179, Art. 1210, 2011.

inadequada, tais critérios podem penalizar injustamente os fornecedores da matéria-prima, uma vez que tais parâmetros são influenciados não só pelos cuidados dispensados ao leite, mas também por características individuais do rebanho, tipo de alimentação, época do ano, condições climáticas, formas de transporte do leite e outros (FONSECA E SANTOS, 2000).

\section{PRODUÇÃO DE LEITE NO MUNDO}

A produção mundial de leite está em crescimento, se expandindo de maneira significativa e contribuindo para o desenvolvimento de alguns poucos países, os quais têm compensado, com alguma folga o pequeno crescimento e/ou a queda na produção de alguns dos principais produtores mundiais (CARVALHO et al., 2006).

O Brasil, ao lado da Argentina, Austrália, Índia, China, Polônia e Ucrânia são países com grande competitividade em custo de produção. Por outro lado, boa parte dos países da União Européia possui custos de produção bem mais elevados e sua competitividade é assegurada por volumosos subsídios e outras formas de proteção de mercado. Portanto, países mais desenvolvidos apresentam maiores produtividades e maior escala de produção, por contar com subsídios, os quais vêm diminuindo a cada ano (CARVALHO et al., 2006). Nos países em desenvolvimento como o Brasil, a produtividade está aumentando e contribuindo para a oferta mundial.

Como se observa dos dados do Quadro 1, a União Européia liderou em 2009 o ranking mundial de produção, com 134 bilhões de litros de leite. O segundo são os Estados Unidos, com 86 bilhões de litros de leite, seguido da Índia com estimativa de 45 bilhões de litros de leite. O Brasil atualmente ocupa o sexto lugar no ranking de produção de leite, com estimativa de 30 bilhões de litros em 2010.

O mercado mundial de lácteos sempre esteve marcado pela instabilidade. As transações comerciais são carregadas de distorções e barreiras ao livre comércio, produto de uma complexa rede de políticas governamentais aplicadas tanto a nível doméstico como internacional. 
WINCK, C.A. et al. Produção de leite no Brasil: qualidade, mercado internacional e agricultura familiar. PUBVET, Londrina, V. 5, N. 32, Ed. 179, Art. 1210, 2011.

As conseqüências dessas distorções são a forte concentração e redução do mercado mundial de lácteos. Os preços muito voláteis, o consumo per capita abaixo do recomendado por organismos internacionais (FAO-OMS) e as crises recorrentes em países que não contam com protecionismo, também são reflexos dos impactos negativos gerados por políticas protecionistas.

Quadro 1: Produção de Leite no mundo (2004-2010)

\begin{tabular}{|l|r|r|r|r|r|r|r|}
\hline & $\mathbf{2 0 0 4}$ & $\mathbf{2 0 0 5}$ & $\mathbf{2 0 0 6}$ & $\mathbf{2 0 0 7}$ & $\mathbf{2 0 0 8}$ & $\begin{array}{c}\mathbf{2 0 0 9} \\
\mathbf{( p )}\end{array}$ & \multicolumn{1}{|c|}{$\begin{array}{c}\mathbf{2 0 1 0} \\
\mathbf{( p 1 )}\end{array}$} \\
\hline Canadá & 7.905 & 7.806 & 8.041 & 8.212 & 8.270 & 8.200 & 8.250 \\
\hline México & 9.874 & 10.164 & 10.391 & 10.657 & 10.909 & 11.132 & 11.355 \\
\hline Estados Unidos & 77.488 & 80.255 & 82.455 & 84.211 & 86.179 & 85.820 & 85.230 \\
\hline Argentina & 9.250 & 9.500 & 10.200 & 9.550 & 10.010 & 10.100 & 10.300 \\
\hline Brasil & 23.317 & 24.250 & 25.230 & 26.750 & 27.820 & 28.795 & 30.235 \\
\hline U. Européia (1) & 133.969 & 134.672 & 132.206 & 132.604 & 133.848 & 133.800 & 134.000 \\
\hline Rússia & 32.000 & 32.000 & 31.100 & 32.200 & 32.500 & 32.500 & 32.800 \\
\hline Ucrânia & 13.787 & 13.423 & 12.890 & 11.997 & 11.524 & 11.300 & 10.961 \\
\hline Índia & 37.500 & 37.520 & 41.000 & 42.890 & 44.500 & 45.865 & 47.670 \\
\hline China & 22.606 & 27.534 & 31.934 & 35.252 & 34.300 & 28.445 & 31.290 \\
\hline Japão & 8.329 & 8.285 & 8.137 & 8.007 & 7.982 & 7.900 & 7.850 \\
\hline Austrália (2) & 10.377 & 10.429 & 10.395 & 9.870 & 9.500 & 9.670 & 9.570 \\
\hline N. Zelândia (3) & 15.000 & 14.500 & 15.200 & 15.640 & 15.141 & 16.601 & 17.021 \\
\hline Total & $\mathbf{4 0 1 . 4 0 2}$ & $\mathbf{4 1 0 . 3 3 8}$ & $\mathbf{4 1 9 . 1 7 9}$ & $\mathbf{4 2 7 . 8 4 0}$ & $\mathbf{4 3 2 . 4 8 3}$ & $\mathbf{4 3 0 . 1 2 8}$ & $\mathbf{4 3 6 . 5 3 2}$ \\
\hline
\end{tabular}

Fonte: USDA Dairy: World Markets and Trad/ December 2009.(p)

Dados preliminares ( $p 1$ ) Projeção (1) Baseado nas entregas (2) Dados referentes ao ano terminado em 30 de junho do ano corrente. (3) Dados referentes ao ano terminado em 31 de maio do ano corrente.

O comércio de lácteos equivale aproximadamente a $7 \%$ da produção mundial, estimada em 549,7 bilhões de litros de leite (FAO, 2007), o que mostra claramente que se trata de um mercado muito reduzido e concentrado. As exportações são dominadas pelos países da União Européia e Oceania (Figura 1). Já as importações concentram-se nos países da Ásia, África e América Latina (Figura 2). 
WINCK, C.A. et al. Produção de leite no Brasil: qualidade, mercado internacional e agricultura familiar. PUBVET, Londrina, V. 5, N. 32, Ed. 179, Art. 1210, 2011.

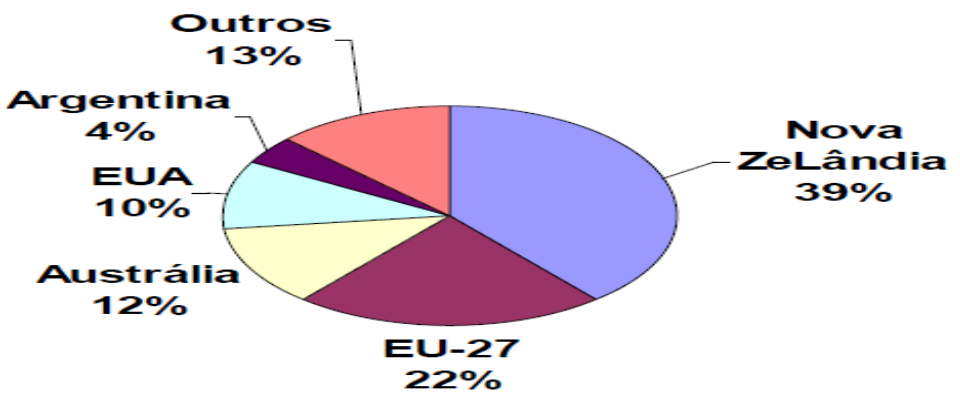

Fonte: USDA, 2008;

Figura 1: Principais exportadores de leite em pó integral e desnatado (2007).

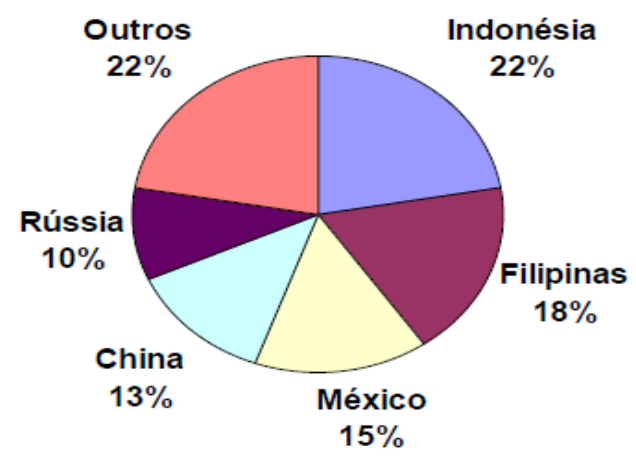

Fonte: USDA, 2008;

Figura 2: Principais importadores de leite em pó integral e desnatado (2007)

Provocado pelo que se convencionou chamar de protecionismo agrícola, nenhum setor do comércio mundial sofre mais distorções do que a agropecuária.

O protecionismo que é definido como um conjunto de práticas e políticas que distorcem a competitividade e a eficiência produtiva tem sido amplamente utilizado pelos países ricos como meio de resguardar seus mercados internos da concorrência de outros países que produzem em condições mais eficientes e competitivas. 
WINCK, C.A. et al. Produção de leite no Brasil: qualidade, mercado internacional e agricultura familiar. PUBVET, Londrina, V. 5, N. 32, Ed. 179, Art. 1210, 2011.

\section{PRODUÇÃO DE LEITE NO BRASIL}

O Brasil é um país que está se destacando na produção de leite e tem ajudado muitas famílias a se reconstituírem financeiramente permanecendo no meio rural, pois faça chuva ou sol, a atividade leiteira não para, é fonte de renda mensal e a mão de obra é quase sempre familiar, o que permite competir em nível de preços no mercado internacional.

Conforme Santos, Marcondes e Cordeiro (2007), a produção leiteira se constitui numa importante atividade econômica e social, que permite um aporte financeiro regular aos pequenos produtores, contribuindo para a sua manutenção no campo e redução do êxodo rural. Entretanto, a cadeia do leite passou por profundas mudanças na economia brasileira, com alteração no ambiente competitivo e implicações para a sustentabilidade, principalmente por parte dos produtores.

As mudanças impostas à pecuária leiteira do Brasil, sobretudo na última década, fizeram com que se desenhasse um novo perfil para o setor. No início dos anos 90, após a abertura do mercado, a Cadeia Produtiva do Leite sofreu uma série de impactos negativos, fruto da falta de uma política coordenada de desenvolvimento da pecuária leiteira (YAMAGUSCHI et al., 2006). As concorrências desleais e predatórias dos países da União Européia e Estados Unidos interferiram bruscamente na competitividade do setor leiteiro no Brasil (MARCONDES, 2005).

Um dos fatores que poderiam auxiliar na melhora das exportações brasileiras, mas não impactam positivamente é o grande rebanho leiteiro brasileiro, visto que nossa produção de leite/vaca/ano não é a adequada. Outro fator primordial para a exportação de produtos lácteos é a qualidade, que se deve principalmente à higiene de ordenha, controle sanitário, conservação do leite antes da industrialização e ausência de resíduos de antibióticos e outros inibidores (GIGANTE, 2004).

Existem importantes desafios na coordenação da cadeia, no fortalecimento de programas institucionais, na eliminação das distorções do mercado internacional (NOGUEIRA, 2007), no aumento de consumo de lácteos, 
WINCK, C.A. et al. Produção de leite no Brasil: qualidade, mercado internacional e agricultura familiar. PUBVET, Londrina, V. 5, N. 32, Ed. 179, Art. 1210, 2011.

na organização dos produtores, na melhoria da qualidade do leite e no crescimento das exportações, entre outros (MARCONDES, 2005).

O Brasil apresenta potencial para se tornar um grande exportador de lácteos, especialmente devido aos baixos custos de produção, competindo em condições de igualdade com outros grandes produtores e exportadores de leite em nível mundial (NERO et al., 2005). Destaca-se ainda que entre as nações mais competitivas na produção de leite, o Brasil é a que tem maior capacidade de expandir em área, qualidade das forragens, melhoramento genético e em manejo (RIBAS, 2004). Por outro lado, mesmo o país possuindo um dos mais baixos custos de produção de leite do mundo, isso ainda não se reverte em competitividade, pois problemas internos relacionados à organização da cadeia produtiva interferem no crescimento das exportações de lácteos (GOMES, 2002).

Para que o Brasil possa se firmar como exportador de lácteos, algumas condições são fundamentais: requerer ação integrada do governo brasileiro e do setor privado para vencer barreiras tarifárias e não-tarifárias impostas; maior coordenação e organização da Cadeia Produtiva do Leite; mais qualidade nos produtos lácteos e a adoção de técnicas modernas de gestão (ICEPA, 2008).

É necessário que a iniciativa privada e o Governo unam esforços para impulsionar as vendas externas do leite e seus derivados, com o intuito de promover o aumento da competitividade da cadeia produtiva do leite no mercado internacional (NOGUEIRA, 2007).

É válido salientar que o governo quer tornar o leite mais acessível às populações carentes, ampliando o número de beneficiados nos programas sociais. Segundo Monardes (2004) as iniciativas aumentarão o consumo do produto, transformando a atividade leiteira na principal fonte de renda e emprego para pequenos produtores (OLIVEIRA et al., 2006), incentivando a produção regional do país.

Evidentemente os desafios enfrentados pelo agronegócio do leite, não poderão ser enfrentados somente pelo setor privado e pela sociedade 
WINCK, C.A. et al. Produção de leite no Brasil: qualidade, mercado internacional e agricultura familiar. PUBVET, Londrina, V. 5, N. 32, Ed. 179, Art. 1210, 2011.

organizada. Necessita-se urgentemente de políticas públicas que, a partir de uma visão integrada, tratem questões imediatas, como tecnologia, crédito, assistência técnica e infraestrutura básica (NERO, 2005). É preciso elaborar novos arranjos para o desenvolvimento rural, pois a capacidade de resposta às necessidades de mudança depende principalmente da capacidade de desenvolvimento adequada à realidade geográfica, ambiental, cultural, política, social e econômica de todos os envolvidos no processo.

Concomitante ao crescimento da produção, também ocorreu um crescimento da demanda nacional e internacional, o que resultou na ampliação do consumo de leite brasileiro e mundial, influenciando as exportações brasileiras, cada vez mais significativas (Figura 3).

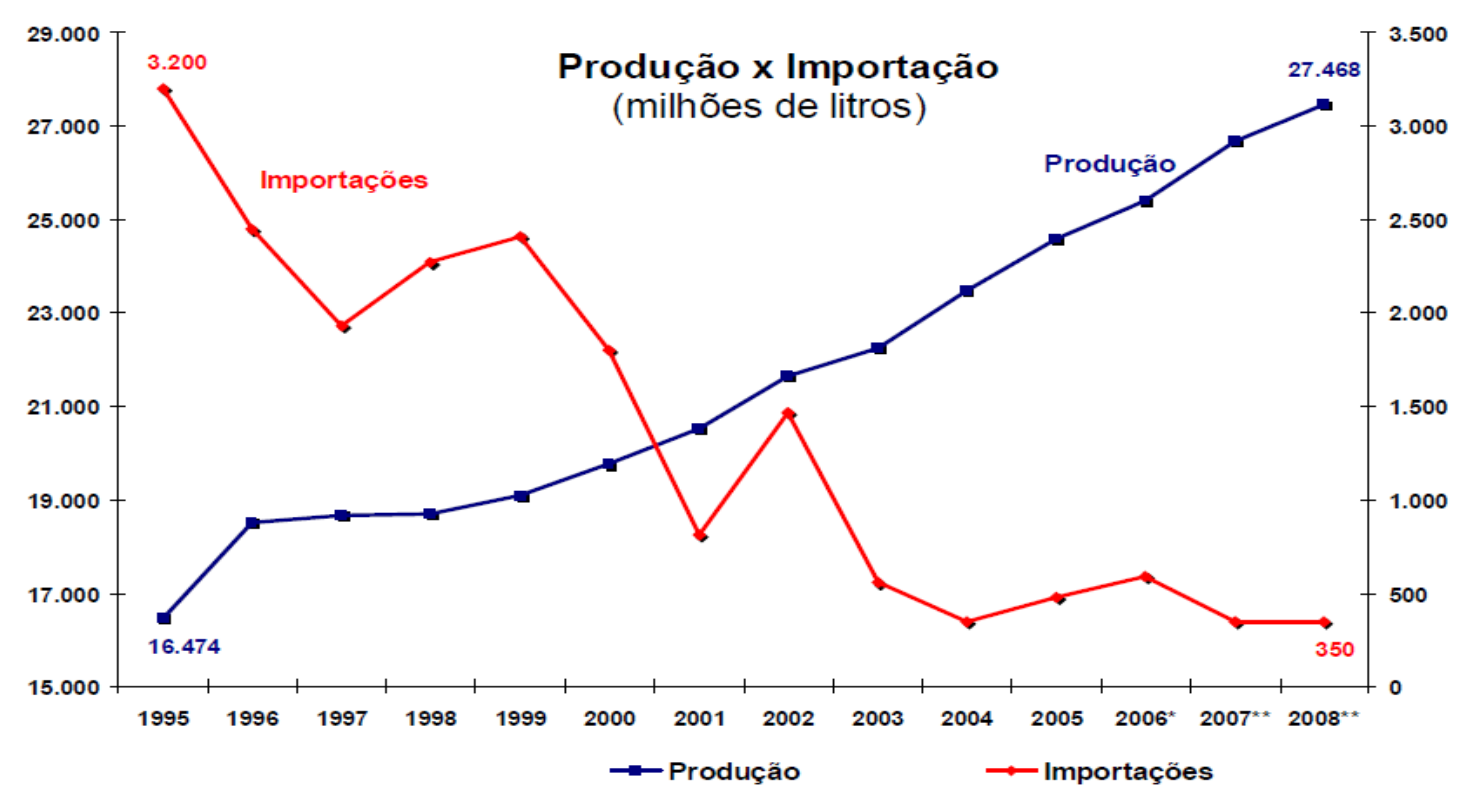

Fonte: Agrostat/MAPA

Figura 3: Produção X Importação em litros de leite (Brasil, 1995-2008)

Isto só reforça a tese de que num quadro de mercado internacional com preços menos distorcidos por políticas de subsídio (OLIVEIRA et al., 2006), o 
WINCK, C.A. et al. Produção de leite no Brasil: qualidade, mercado internacional e agricultura familiar. PUBVET, Londrina, V. 5, N. 32, Ed. 179, Art. 1210, 2011.

Brasil tem condições não apenas de reduzir sensivelmente as importações, como de ampliar as exportações (IBGE, 2008).

No início da década de 90, importava-se leite subsidiado de outros países, burlando a gravação de $30 \%$ imposta pelo Brasil, ganhando os importadores até $14 \%$, diferença das tarifas dos dois países para compras de fora do bloco. Por causa da fragilidade originada pela grande desregulamentação mercadológica que na prática significou um desregramento, chegou-se ao ponto de ocorrerem excessivas importações desleais, a preços de dumping e/ou subsídios.

No final de década de 90, a investigação de dumping feita pelo governo brasileiro contra exportadores da Nova Zelândia, União Européia, Argentina e Uruguai, concluída no final de 2000, resultou na aplicação de tarifas e estabelecimento de acordos de preços a partir de fevereiro de 2001, em relação às empresas dos países investigados.

A aplicação do direito antidumping somada à inclusão do leite em pó, dos queijos e do soro de leite na Lista de Exceções à Tarifa Externa Comum (TEC) do MERCOSUL, com imposto de $27 \%$, proporcionou um novo estímulo à produção de leite no Brasil.

O País, que disputava com México e Argélia o título de maior importador de lácteos do mundo, passou por um processo intenso de substituição das importações até que, em 2004, pela primeira vez foi superavitário na balança comercial (Figura 4).

Em consequência à redução das importações, houve crescimento significativo da participação de leite nacional no consumo aparente. Em 1997, os 1,3 bilhões de litros de leite em pó importados corresponderam a 10,3\% do consumo. Em 2007, a participação do leite importado foi de apenas 350 milhões de litros, $1,3 \%$ do consumo.

A substituição das importações permitiu ampliar a produção nacional em 4,4\% ao ano a partir de 2001. Da mesma forma, o Valor Bruto da Produção de Leite (VBP) passou de R\$9,3 bilhões em 2001 para R\$16,0 milhões em 2006, incremento de $72,1 \%$ no período (Figura 5 ). 
WINCK, C.A. et al. Produção de leite no Brasil: qualidade, mercado internacional e agricultura familiar. PUBVET, Londrina, V. 5, N. 32, Ed. 179, Art. 1210, 2011.

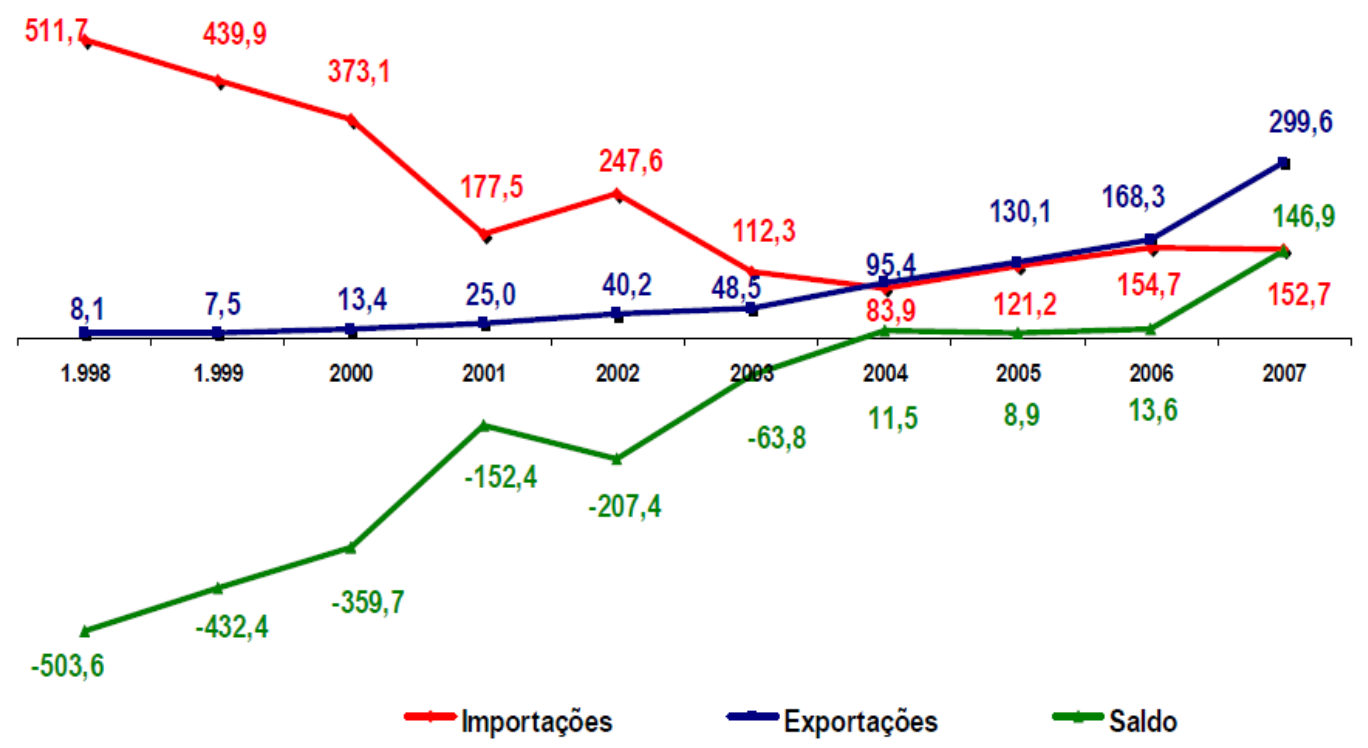

Fonte: Agrostat/MAPA

Figura 4: Balança Comercial de Lácteos 1998-2007 - Brasil

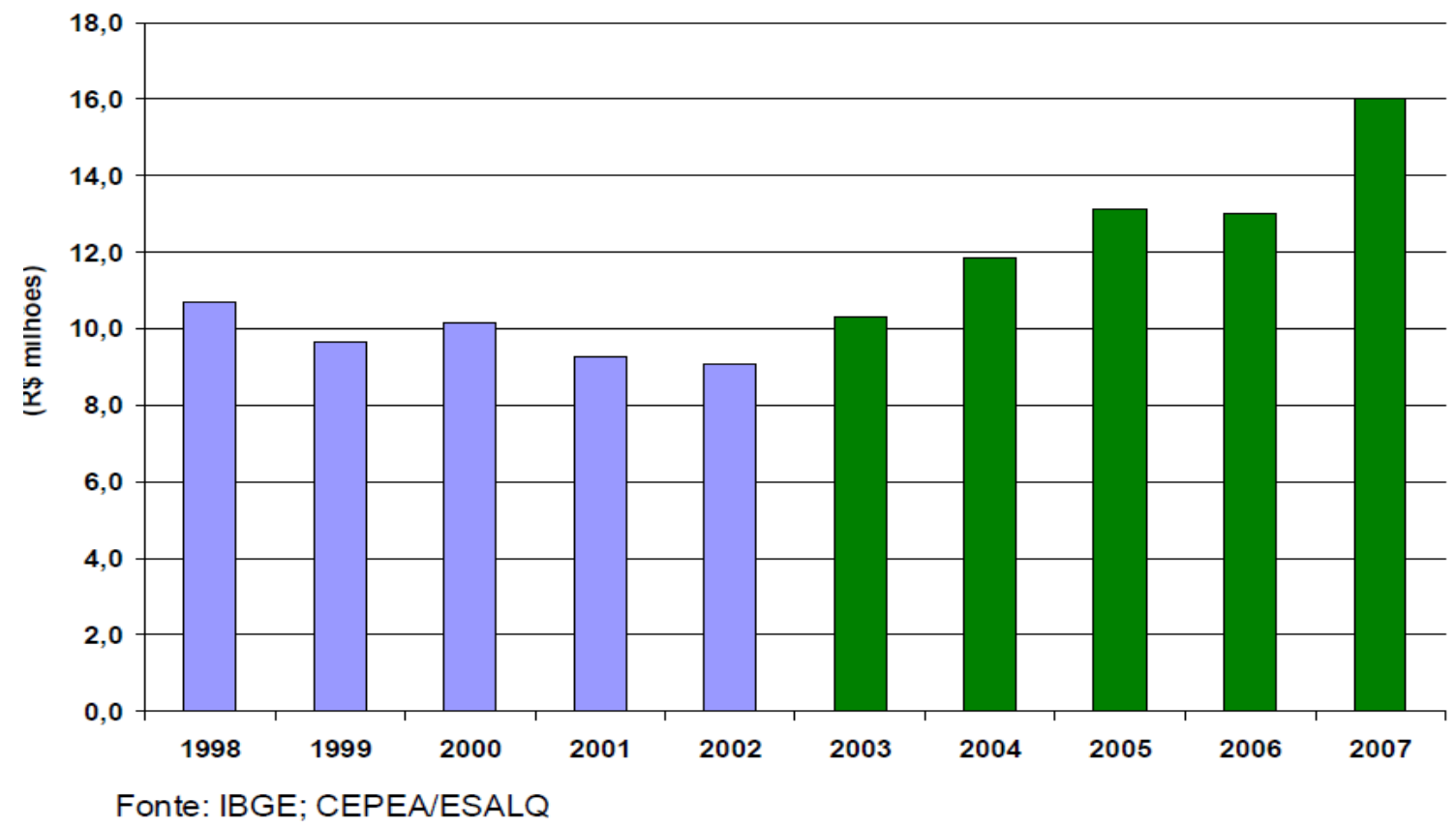

Figura 5: Valor Bruto da Produção de Leite 1998-2007 (Brasil) 
WINCK, C.A. et al. Produção de leite no Brasil: qualidade, mercado internacional e agricultura familiar. PUBVET, Londrina, V. 5, N. 32, Ed. 179, Art. 1210, 2011.

O maior desafio da pecuária leiteira nos dias atuais é ter, no mundo globalizado, uma presença agressiva e permanente, e não marginal como tem sido até agora. A melhor forma de fazer essa inserção é seguir o mesmo caminho de outros países, que criaram uma organização exclusiva para essa tarefa.

Para isso, a iniciativa privada e o governo precisam unir esforços para impulsionar as vendas externas de leite e derivados, criando um programa de incentivo às exportações, incluir o leite na Política de Garantia de Preços Mínimos, possibilitando a implementação de mecanismos de comercialização de produtos lácteos, criar um fundo para a promoção do consumo de leite e derivados no mercado doméstico, e incentivar o uso de leite nacional na merenda escolar, estimulando as compras nos estados e municípios.

Nesse ambiente competitivo, se verificam alterações de ordem sanitária através da Normativa 51, que passou a requerer do setor produtivo, novos padrões de qualidade do leite, maior controle sanitário de rebanhos e coleta sob refrigeração. (SANTOS; MARCONDES; CORDEIRO, 2007).

Estas alterações baseadas na Normativa 51 demandam investimentos em todos os elos das cadeias e no segmento da produção. Os produtores tendem a se adequar a esses padrões de produção, tendo um aperfeiçoamento tecnológico, especialização, aquisição de novos equipamentos e adequação de escalas compatíveis a seu nível de tecnificação.

\section{IMPORTANCIA DA PRODUÇÃO DE LEITE NA AGRICULTURA BRASILEIRA}

Ao longo dos últimos anos, a atividade leiteira vem tendo cada vez mais importância econômica e social para o setor agrícola brasileiro. Atualmente, se constitui um segmento estratégico, segundo Santos, Marcondes e Cordeiro (2007), para a vida de um significado contingente de produtores rurais, particularmente a família, que é responsável pelo movimento econômico de grande parte dos municípios do país.

A redução de alternativas de renda que muitos produtores são submetidos fez com que houvesse um aumento da importância da produção 
WINCK, C.A. et al. Produção de leite no Brasil: qualidade, mercado internacional e agricultura familiar. PUBVET, Londrina, V. 5, N. 32, Ed. 179, Art. 1210, 2011.

leiteira, visando melhorar o sistema de produção, permitindo aumentar produtividade em relação aos custos.

A cadeia produtiva do leite ainda sofre muito com a pouca articulação dentro das diferentes esferas do setor publico e privado e há, ainda, a necessidade de novos mecanismos para dar incentivo e garantir a produção para que seja valorizada e o primeiro passo seria que o governo brasileiro estabelecesse um preço mínimo do leite.

O Brasil é um importante produtor internacional de alimentos e a produção leiteira advém principalmente da pequena propriedade rural familiar. Por isso é importante que se aprofunde a análise de informações quantitativas e qualitativas sobre a produção de leite para, assim, conhecer o comportamento da cadeia de produção.

Isto ocorreu devido à instabilidade da renda na agropecuária, decorrente de exigência de escala de produção, de aperfeiçoamento tecnológico, das condições climáticas, da tendência de queda nos preços de produtos agrícolas e da perda de competitividade para outras cadeias agroindustriais. (SANTOS; MARCONDES; CORDEIRO, 2007).

A bovinocultura de leite, para Berto e Berto (2007), tem sido apontada como uma alternativa econômica para um grande número de produtores excluídos da suinocultura e da avicultura e, também, como uma atividade que apresentaria menor impacto no ambiente devido a sua menor concentração de dejetos. Além disso, a pastagem pode servir como destino dos dejetos da avicultura e da suinocultura.

A solução para esses produtores passa pela elaboração de estratégias de viabilização do agronegócio. É imperativo que os produtores adotem o processo de aprendizagem de todo um conjunto de atividades pouco usuais nos modos tradicionais de produção. Além da utilização de tecnologia e novas formas de organização coletiva, também é imprescindível trabalhar com a gestão de empreendimento.

Deve-se levar em conta, sempre o fato de que o que diferencia uma propriedade desenvolvida de uma não-desenvolvida é exatamente seu grau de 
WINCK, C.A. et al. Produção de leite no Brasil: qualidade, mercado internacional e agricultura familiar. PUBVET, Londrina, V. 5, N. 32, Ed. 179, Art. 1210, 2011.

organização. Quanto mais organizados forem os membros da família em relação às suas propriedades rurais, mais transparente, democrática e capaz de enfrentar desafios essa propriedade será.

A verdade é que os agricultores não precisam apenas de teorias, mas também orientações e instruções práticas, de modo a poderem aplicar seus conhecimentos e sua boa vontade em prol de seu empreendimento, fazendo manejo correto de seu rebanho, tornando assim, sua atividade mais lucrativa.

A globalização da economia explica as necessidades de ajustes no novo modelo de desenvolvimento rural. Deve-se ressaltar que o setor agropecuário exerce um papel relevante nos aspectos sociais e econômicos, e que, a agricultura familiar tem capacidade de crescer e manter-se em destaque, apesar do cenário ser marcado por problemas de instabilidade e transformação.

"A delimitação do que seja produção familiar no âmbito do setor agropecuário por si só já constitui uma atividade complexa, quanto mais circunscrevê-la às atividades da pecuária leiteira", afirma Bressan (2003, p. 295).

Analisando-se a Tabela 1, percebe-se que o leite é fundamental para a manutenção da família agricultora no campo, não importando o nível de capitalização da propriedade e nem o tipo de mão de obra utilizada.

Tabela 1 - Importância da atividade de leiteira para os produtores familiares

\begin{tabular}{llll}
\hline \multicolumn{3}{c}{ Variável } & \% \\
\hline $\begin{array}{l}\text { Presença do leite em propriedades de agricultores } \\
\text { capitalizados }\end{array}$ & 67 \\
$\begin{array}{l}\text { Presença do leite em propriedades de agricultores em } \\
\text { processo de capitalização }\end{array}$ & 58 \\
$\begin{array}{l}\text { Mão-de-obra familiar utilizada na pecuária de leite } \\
\text { Pequeno Produtor }\end{array}$ & 65 \\
\hline
\end{tabular}

Fonte: Estatísticas da Pecuária de Leite (INCRA/FAO - 2003).

Em suma a agregação de valor ao leite produzido pelas unidades familiares, requer acima de tudo a mobilização e o preparo do grupo, para que 
WINCK, C.A. et al. Produção de leite no Brasil: qualidade, mercado internacional e agricultura familiar. PUBVET, Londrina, V. 5, N. 32, Ed. 179, Art. 1210, 2011.

tenham condições para enfrentar os desafios impostos pelo processo de mudança. Uma das formas de aumentar a renda do pequeno produtor de leite, sem exigir sua participação diretamente do processo é o fortalecimento nas negociações com compradores, ofertando o produto de forma coletiva, ancorado em contratos de produção.

Existem algumas medidas relevantes para dar maior transparência e equidade no agronegócio do leite, entre elas: marketing para estimular consumo e fortalecer o setor (SILVA e BATALHA, 2007), fortalecimento do associativismo, combate a fraudes, reforma tributária, contratos de fornecimento e critérios de pagamento antecipados aos produtores, linhas de credito, consolidação e alongamento de dívidas e programa de retenção de matrizes (WAGNER et al., 2004). Fundamental também é melhorar o pagamento aos produtores de leite, incentivando através de benefícios e/ou incentivos, remunerando por qualidade, atitude que, alguns países adotaram para incentivar a melhoria da qualidade do leite (OLIVEIRA et al., 2001).

Segundo Ribas et al. (2004) a implantação de sistemas de pagamento por qualidade, com base nos resultados das análises de gordura, proteína, lactose, e/ou de sólidos totais, e da contagem de células somáticas, possibilitará ao país se enquadrar nos padrões internacionais de qualidade, necessários à manutenção e conquista de oportunidades de mercado.

Programas de pagamento por qualidade são adotados em países de pecuária desenvolvida, com o objetivo de incentivar a melhoria da qualidade do leite de seus fornecedores (WELLS e OTT, 1998), o que seria um grande avanço na cadeia leiteira do Brasil. Estes programas definem classes de qualidade para cada variável, com remuneração diferenciada para cada classe. Iniciativas desta natureza também começam a ser adotadas no Brasil. Por exemplo, o programa proposto por uma indústria nacional, prevê que o leite com CBT inferior a $100 \mathrm{mil}$ UFC/ml de leite, será remunerado acima de certo valor base, enquanto que o leite com contagem superior a $400 \mathrm{mil}$ UFC/ml será penalizado, sendo remunerado abaixo do valor base. Este conceito também já 
WINCK, C.A. et al. Produção de leite no Brasil: qualidade, mercado internacional e agricultura familiar. PUBVET, Londrina, V. 5, N. 32, Ed. 179, Art. 1210, 2011.

foi aplicado às outras variáveis como teor de gordura, proteína e CCS em outra empresa.

Pode-se salientar que o governo brasileiro quer tornar o leite mais acessível às populações carentes, ampliando o número de beneficiados nos programas sociais. Segundo Wagner et al. (2004) as iniciativas aumentarão o consumo do produto, transformando a atividade leiteira na principal fonte de renda e trabalho para pequenos produtores (OLIVEIRA et al., 2006), incentivando a produção regional do país.

É fundamental que se criem alternativas voltadas para aos pequenos produtores, bem como programas de treinamento e capacitação de produtores na atividade leiteira, a fim de buscar soluções de acordo com a realidade das propriedades rurais e no contexto socioeconômico que constitui seu ambiente de trabalho (BATALHA e SILVA, 2007), linhas de crédito especiais, de modo a auxiliar o desenvolvimento do agronegócio, já que os recursos disponíveis são insuficientes aos empresários rurais, além de juros compatíveis com a atividade (FIGUEIREDO e PAULILLO, 2006).

Evidentemente os desafios enfrentados pelo agronegócio do leite, não poderão ser enfrentados somente pelo setor privado e pela sociedade organizada. Necessita-se urgentemente de políticas públicas que, a partir de uma visão integrada, tratem questões imediatas, como tecnologia, crédito, assistência técnica e infraestrutura básica (NERO, 2005). É preciso elaborar novos arranjos para o desenvolvimento rural, pois a capacidade de resposta às necessidades de mudança depende principalmente da capacidade de desenvolvimento adequada à realidade geográfica, ambiental, cultural, política, social e econômica de todos os envolvidos no processo (RANZAM et al., 2006).

\section{CONSIDERAÇÕES FINAIS}

Uma das preocupações do setor leiteiro nacional é a manutenção dos produtores de leite na atividade, considerando implantação da IN 51 (BRASIL, 2002) e a inserção mercadológica do leite brasileiro a nível mundial. Não há 
WINCK, C.A. et al. Produção de leite no Brasil: qualidade, mercado internacional e agricultura familiar. PUBVET, Londrina, V. 5, N. 32, Ed. 179, Art. 1210, 2011.

dúvidas que os mercados interno e externo exigem cada vez mais qualidade, e isto exige esforços de toda a cadeia produtiva, em especial dos produtores, que precisam alterar sua matriz produtiva, para alcançar os patamares exigidos para qualidade microbiológica e ausência de resíduos.

Embora a IN 51 não exija a compra de equipamentos (principalmente ordenhadeiras e resfriadores), parte considerável dos produtores terá que modificar instalações, equipamentos, sistemas de ordenha e até o manejo adotado com os animais, para conseguir alcançar os padrões mínimos de qualidade exigidos.

A indústria tem interesse em que os produtores consigam atingir as metas estabelecidas pela normativa, afinal, da matéria-prima recebida com qualidade é que se atinge a produção de leite e derivados com condições mercadológicas competitivas para o mercado. Consequentemente, é necessário empenho por parte do setor industrial na busca pela melhoria da qualidade do leite recebido, promovendo a melhoria da assistência técnica fornecida aos produtores, incremento nos valores pagos por litro, tanto em volume como em qualidade e na efetiva participação do setor industrial na busca por novos mercados.

Analisando-se a importância da qualidade do leite para a manutenção e ampliação dos mercados conquistados, a geração de renda para os produtores, e a manutenção das famílias na agricultura, deve-se considerar que caso não ocorra uma transformação na cadeia produtiva do leite no Brasil, os produtores não conseguirão manter-se na atividade, e poderá ocorrer uma sensível queda no número de produtores e possivelmente nos índices de volume de produção.

Embora o preço do leite pago ao produtor tenha reagido durante os últimos anos, os custos produtivos também acompanharam a tendência de valorização de preços, sendo assim, praticamente não sobram recursos para o investimento na melhoria da produção.

Sem que haja remuneração pela qualidade do leite, e/ou incentivos aos produtores para a adequação do sistema de produção, milhares serão excluídos do processo produtivo e acabarão tendo que buscar outras fontes de 
WINCK, C.A. et al. Produção de leite no Brasil: qualidade, mercado internacional e agricultura familiar. PUBVET, Londrina, V. 5, N. 32, Ed. 179, Art. 1210, 2011.

renda para a manutenção mínima da família, além de impedir a produção de leite para subsistência.

\section{REFERÊNCIAS}

AGROSTAT - Ministério da Agricultura, Pecuária e Abastecimento (MAPA) Diagnósticos da Pecuária Brasileira (1990-2008) Disponível em: <http://www.agricultura.gov.br/> Acesso em: 24 de julho de 2010.

BERTO, L. J.; BERTO, J. L. Estimativa do saldo anual de $\mathbf{N}$ em sistemas de criação de vacas leiteiras no Oeste de Santa Catarina. Ciência Rural v.37 n.2 Santa Maria, mar./abr. 2007.

BRASIL. Instrução Normativa $n^{\circ}$. 51 , de 20 de setembro de 2002. Aprova os regulamentos técnicos de produção, identidade, qualidade, coleta e transporte de leite. Diário Oficial da União, Brasília, Seção I, p.13, 21 set. de 2002.

BRESSAN, M. et al. Gestão Ambiental e Políticas para o Agronegócio do Leite. Juiz De Fora: EMBRAPA, 2003.

CARVALHO, G. R.; CARNeIRO, A. V.; STOCK, L. A. Comunicado Técnico 51 . O Brasil no cenário mundial de lácteos. Juiz de Fora- MG. Outubro 2006. Embrapa Gado de Leite.

CERVO, A. L.; BerVIAN, P. A. Metodologia Científica. 4 ed. São Paulo : Makron, 1996.

DÜRR, J. W. (Org.) o compromisso com a qualidade do leite no Brasil. Passo Fundo: Editora Universitária, 2004.

FAO - FOOD AND AGRICULTURE ORGANIZATION OF THE UNITED NATIONS - FAO. Statistical databases. Disponível em: http://apps.fao.org/ Acesso em: 19 de julho de 2010.

FIGUEIREDO, J. C.; PAULILLO, L. F. Gênese, modernização e reestruturação do complexo agroindustrial lácteo brasileiro. Revista Organizações Rurais Agroindustriais. v. 7, n. 2, p. 173-187, Lavras, 2006.

FONSECA, L. F. L. da; SANTOS, M. V. dos. Conceitos básicos sobre composição do leite e métodos utilizados. In: Fonseca L. F. L. da et al. Curso online sobre qualidade do leite. São Paulo: Milkpoint. 2000.

GIGANTE, M. L. Importância da qualidade do leite no processamento de produtos lácteos. In: DÜRR, 1. W. (Org.) O compromisso com a qualidade do leite no Brasil. Passo Fundo: Editora Universitária, 2004.

GIL, A. C. Métodos e Técnicas de Pesquisa Social. 6 ed. São Paulo: Atlas, 2008.

GOMES, M. F. Modernização do sistema de inspeção sanitária federal de leite e derivados e os programas de segurança alimentar. In: PORTUGAL, J. A.;

NEVES, B. S.; OLIVEIRA, A. C. S.; SILVA, P. H. F.; BRITO, M. A. V. P. (Ed.). Segurança alimentar na cadeia do leite. Juiz de Fora: EPAMIG; Instituto de Laticínios Cândido Tostes; Embrapa Gado de Leite, 2002. p. 115-179.

IBge - instituto bRASIleiro de PeSQuisa geOgráficA. Produção de leite no Brasil. Brasília: IBGE, 2008.

ICEPA. Síntese Anual da Agricultura de Santa Catarina 2006-2007. Florianópolis: ICEPA, 2008. 
INCRA - INSTITUTO NACIONAL DE COLONIZAÇÃO E REFORMA AGRÁRIA. Novo retrato da agricultura familiar - o Brasil redescoberto. Projeto de Cooperação Técnica INCRA/FAO. Brasília. Fev, 2003. Site: http://www.incra.gov.br/fao/ Acesso em 15 de agosto de 2010.

MARCONDES, T. Leite - Novos números sobre a produção mundial. Florianópolis: ICEPA, 2005.

MONARDES, H. Reflexões sobre a qualidade do leite. In: DÜRR, 1. W. (Org.) $O$ compromisso com a qualidade do leite no Brasil. Passo Fundo: Editora Universitária, 2004.

NERO, L.A.; MATTOS, M. R. de; BELOTI, V. et al. Leite cru de quatro regiões leiteiras brasileiras: perspectivas de atendimento dos requisitos microbiológicos estabelecidos pela Instrução Normativa 51. Ciência e Tecnologia de Alimentos, jan./mar. 2005, vol.25, n.1, p.191-195.

NOGUEIRA, M.P. Leite: as cicatrizes de 2006 e as perspectivas para 2007. Balde Branco, São Paulo, n. 507, p. 22-25, jan. 2007.

OLIVEIRA, C.A. et al. Projeto Alfa Neruda: Algumas características das propriedades leiteiras brasileiras. In: Congresso Panamericano de Leite, 9, 2006, Porto Alegre. Anais... Juiz de Fora, Embrapa Gado de Leite, 2006. 1 CD-ROM.

OLIVEIRA, T. B. A. et al. Índices técnicos e rentabilidade da pecuária leiteira. Scientia Agrícola, Piracicaba, v. 58, n.4, p. 56-65, out./dez. 2001.

PHILPOT, W. N: Importância da qualidade de células somáticas e outros fatores que afetam a qualidade do leite. In: I Simpósio Internacional sobre qualidade do leite, 1998, Curitiba. Anais. Curitiba: UFPR. 1998.

RANZAN, O. et al. Resultados econômicos de sistemas de produção de leite com diferentes níveis tecnológicos na Cooperativa Agropecuária Castrolanda, Castro, PR. In: Congresso Panamericano de Leite, 9, 2006, Porto Alegre. Anais... Juiz de Fora, Embrapa Gado de Leite, 2006. 1 CD-ROM.

RIBAS, N. P. et al. Sólidos totais do leite em amostras de tanque nos estados do Paraná, Santa Catarina e São Paulo. Revista Brasileira de Zootecnia, nov./dez. 2004, vol.33, no.6, supl.3, p.2343-2350.

SANTOS, O. V. dos; MARCONDES, T.; CORDEIRO, J. L. F.. Estudo da Cadeia do Leite em Santa Catarina: prospecção e demandas. Florianópolis: EPAGRI, 2007. 90p. (EPAGRI. Documentos, 230).

SILVA, A. L.; BATALHA, M. O. Marketing estratégico aplicado ao agronegócio. In: BATALHA, M. O. (Org) Gestão Agroindustrial, São Paulo, SP: Atlas, 2007, 690 p., ed. 3, v. 1. p. 23-62.

USDA - United States Department of Agriculture (USDA) Disponível em: <http://usda.mannlib.cornell.edu/reports/nassr/dairy/pmp-bb/2009 > Acesso em: 20 de julho de 2010.

USDA - Produção mundial de leite: produção, exportações e importações Disponível em: http://usda.mannlib.cornell.edu/reports/nassr/dairy/pmpbb/2005/ Acesso em: 15 de maio de 2010.

WAGNER, S. A.; GEHLEN, I.; WIEST, J. M. Padrão tecnológico em unidades de produção familiar de leite no Rio Grande do Sul relacionado com diferentes tipologias. Ciência Rural, Santa Maria, v. 34, n.5, p. 1579-1584, set./out., 2004.

WEELS, S. J.; OTT, S. L. What is the current milk quality in the USA. In: National Mastitis Council Annual Meeting, 37., 1998, St. Louis. Proceedings... Madison: National Mastitis Council, 10-18,1998. 
YAMAGUCHI, L.C.T. et al. Dinâmica da produção de leite no Brasil: período 1990-2004. In: Congresso Panamericano de Leite, 9, 2006, Porto Alegre. Anais... Juiz de Fora, Embrapa Gado de Leite, 2006. 